\title{
Effects of Syngas Particulate Fly Ash Deposition on the Mechanical Properties of Thermal Barrier Coatings on Simulated Film-Cooled Turbine Vane Components
}

\author{
Kevin Luo', Andrew C. Nix¹, Bruce S. Kang², Dumbi A. Otunyo ${ }^{2}$ \\ ${ }^{1}$ Center for Alternative Fuels, Engines and Emissions, Department of Mechanical and Aerospace Engineering, \\ Morgantown, USA \\ ${ }^{2}$ Department of Mechanical and Aerospace Engineering, Morgantown, USA \\ Email: kluo1@mix.wvu.edu, andrew.nix@mail.wvu.edu
}

Received 7 September 2014; revised 17 October 2014; accepted 13 November 2014

Copyright (C) 2014 by authors and Scientific Research Publishing Inc.

This work is licensed under the Creative Commons Attribution International License (CC BY). http://creativecommons.org/licenses/by/4.0/

(c) (i) Open Access

\begin{abstract}
Research is being conducted to study the effects of particulate deposition from contaminants in coal synthesis gas (syngas) on the mechanical properties of thermal barrier coatings (TBC) employed on integrated gasification combined cycle (IGCC) turbine hot section airfoils. West Virginia University (WVU) had been working with US Department of Energy, National Energy Technology Laboratory (NETL) to simulate deposition on the pressure side of an IGCC turbine first stage vane. To model the deposition, coal fly ash was injected into the flow of a combustor facility and deposited onto TBC coated, angled film-cooled test articles in a high pressure (approximately $4 \mathrm{~atm}$ ) and a high temperature $(1560 \mathrm{~K})$ environment. To investigate the interaction between the deposition and the TBC, a load-based multiple-partial unloading micro-indentation technique was used to quantitatively evaluate the mechanical properties of materials. The indentation results showed the Young's Modulus of the ceramic top coat was higher in areas with deposition formation due to the penetration of the fly ash. This corresponds with the reduction of strain tolerance of the $\mathbf{7 \%}$ yttria-stabilized zirconia (7YSZ) coatings.
\end{abstract}

\section{Keywords}

IGCC Gas Turbine Thermal Barrier Coatings, Coal Syngas, Fly Ash Deposition, Micro-Indentation, Strain Tolerance 


\section{Introduction}

Development and analysis of gas turbine coating systems are being driven worldwide in an effort to produce higher efficiency and more durable turbine systems. Thermal barrier coatings (TBCs) are designed to withstand high temperatures and protect the component substrate below the coatings. The top layer of a TBC system typically contains the ceramic top coat comprised of YSZ (Zirconia, $\mathrm{ZrO}_{2}$ partially stabilized by yttria 7 - 8 wt\% $\mathrm{Y}_{2} \mathrm{O}_{3}$ ) [1]. The purpose of the layer is to extend the life of the metallic substrate components below the YSZ coatings by insulating them at turbine operating temperatures, and lowering the surface temperature of the metallic substrate. Two common methods for TBC application are air plasma sprayed (APS) and electron-beam physical-vapor deposition (EB-PVD). An EB-PVD coating is typically preferred for its strain tolerance provided by its columnar grain microstructure [2]. A metallic bond coat (BC) is applied to the substrate in order to adhere the top coat to the substrate and to provide an aluminum reservoir for alumina, $\alpha-\mathrm{Al}_{2} \mathrm{O}_{3}$, formation in the thermally grown oxide (TGO). TGO develops between the bond coat and ceramic top coat of the system under thermal operating conditions. The low thermal conductivity $(k)$ of the TBC relative to the substrate allows for the gas turbine system to run at higher gas temperatures than the melting point of the substrate. The gas turbine efficiency will subsequently be higher.

Several TBC durability issues arise from the higher operating temperatures. One particular issue is the effects of molten deposits that adhere on top of the YSZ coatings. Molten deposits in the gas turbines are due to impurities that enter through the inlet air or the upstream combustion of particulate laden alternative fuels such as coalderived synthesis gas (syngas). Sand or volcanic ash ingestion is among the most common impurities found in aero engines. These deposits can degrade the components within the turbine system or inhibit performance of cooling designs.

Calcium-magnesium-alumino-silicate (CMAS) attacks form the most common molten deposits on TBCs. The deposits from CMAS develop as siliceous debris is introduced through the intake air and melt and adhere on top of the TBC once the temperatures exceed $1150^{\circ} \mathrm{C}$. Wellman and Nicholls [3] found that CMAS causes severe damage to the column morphology from dissolution of the YSZ which reduces the TBCs insulating properties and strain tolerance, changes in the YSZ crystal structure from tetragonal to monoclinic from depletion in yttria, and an increase in the erosion rate on EB-PVD TBCs. Levi, Hutchinson, Vidal-Sétif, and Johnson [4] found that CMAS deposits infiltrated the intercolumnar gaps of the EB-PVD top coat towards the TGO and de-stabilized the non-transformable, metastable tetragonal t'-YSZ top coat along the way. The infiltration can lower the strain tolerance after the CMAS salt cools within the TBC due to the stress mismatch from coefficient of thermal expansion differences.

Volcanic ash can also form molten deposits onto the TBC. An eruption of the Eyjafjallajökull volcano in Iceland in 2010 sent volcanic ash clouds in which a jet aircraft can inadvertently fly through. The ash from Eyjafjallajökull was found to form a glass at roughly $1160^{\circ} \mathrm{C}$. Drexler et al. [5] found that the molten ash infiltrates the pores and cracks of the APS top coat causes similar degradation as the molten CMAS.

The purpose of the current study is to understand the effects of particulate deposition due to coal syngas combustion in a high-pressure, high-temperature environment on the mechanical properties of TBCs of gas turbine components. The National Energy Technology Laboratory (NETL) Aerothermal Test Facility was the site where the modeling of fly ash and simulation of deposition for 10,000 operating hours in a 6-hour test on angled test articles was conducted [6]. The accelerated deposition process takes place at a pressure of approximately $4 \mathrm{~atm}$ and a gas temperature of $1560 \mathrm{~K}$. The processed fly ash had its Stokes number and particulate loading matched between the laboratory and engine conditions.

Understanding of the effects of particulate deposition on the TBCs can improve the gas turbine durability and efficiency. The current study examines the influence of the fly ash deposition on the mechanical properties, specifically the Young's modulus, of the ceramic top coat. Eberl et al. found that a typical EB-PVD YSZ coating has an elastic modulus of 15 - 30 GPa [7]. To determine the Young's modulus values of the areas of TBC with varying amount of deposition, a table top load-based multiple-partial unloading micro-indentation system is used. Studies by Tannenbaum [8] and Otunyo [9] have used the micro-indentation systems at WVU to measure the Young's modulus of the TBC systems. Their studies were able to predict future spallation locations in areas of theYSZ coatings that exhibited increases in surface stiffness. With the use of the micro-indentation system, the modulus of elasticity can be evaluated for unexposed and deposition infiltrated portions of the simulated test articles. 


\section{Test Articles and Experimental Methods}

In the current study, the test articles were designed to simulate the pressure side of a first stage turbine vane with incline angles of $10^{\circ}$ and $20^{\circ}$. The substrate material of the test articles is HAYNES 230 (HA230) alloy due to its excellent high-temperature strength, resistance to oxidizing environments, and lower thermal expansion characteristics compared to most high-temperature alloys. The test article has four round cooling holes, each with a 3.9 $\mathrm{mm}$ diameter placed on the face at an angle $30^{\circ}$ to the surface. Using Reynolds similarity, the cooling holes were scaled to $8 \times$ the size of an actual gas turbine cooling hole. Cooling air is delivered to the face with a hollowed out backside from a connected high pressure air system.

The thermal barrier coatings were applied to each test article using a directed vapor deposition (DVD) process [10]. The DVD process produces coatings similar to those of the EB-PVD but has a more efficient deposition process. It features non line-of-sight deposition and controlled intermixing during multiple source evaporation which allows for novel coating architectures and deposition on complex engine components. Approximately 400 $\mu \mathrm{m}$ of ceramic top coat layer was applied as 7\% Yttrium Stabilized Zirconia (7YSZ). A $\Upsilon$ - $\Upsilon^{\prime}$ platinum aluminide (PtAl) bond coat, developed by Brian Gleeson at the University of Pittsburgh [11], was applied with an approximate thickness of 15 - $20 \mu \mathrm{m}$. The cooling holes were masked during the coating process, which created a shallow trench, a configuration used in modern gas turbine components [12]. Figure 1 contains images of two angled test articles after TBC application [6].

To simulate the syngas contaminants, fly ash was processed by drying, grinding, and filtering and injected into the high-pressure combustion facility. After filtration, the mean particle size of the processed fly ash was measured by a LS Particle Size Analyzer to be approximately $13 \mu \mathrm{m}$. Table 1 displays the composition of the bituminous fly ash in the current study [6]. To scale the particle inertial characteristics and set the desired mean particle diameter, the Stokes number was matched between engine conditions and laboratory [13]. The Stokes numbers were calculated for fly ash particles that range from $0.5 \mu \mathrm{m}$ to $47 \mu \mathrm{m}$ for the engine and laboratory conditions based on mainstream temperature, fly ash density, hole diameter, mainstream viscosity, mainstream velocity, and particle size [6]. Lastly, fly ash particulate was injected into the high pressure combustion rig using a PS-20 Scitek pressurized particle seeder. Particulate loading (ppmw-hr) was matched for loadings that exist in actual gas turbine engines that operate over a period of 10,000 hours. The particulate concentration (ppmw) was increased to reduce the required hours in the laboratory. The particulate loading comparison is shown in Table 2 [6].

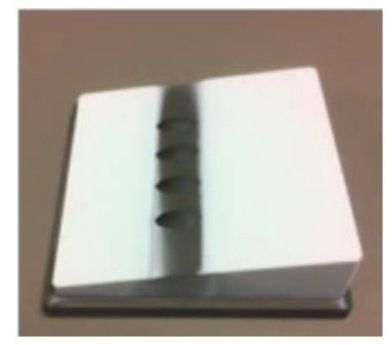

(a)

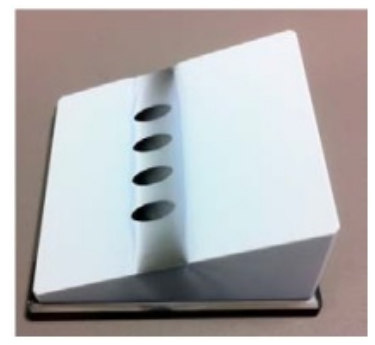

(b)

Figure 1. Photographs of the (a) $10^{\circ}$ and (b) $20^{\circ}$ test articles with TBC before deposition testing.

Table 1. Bituminous coal ash composition [6].

\begin{tabular}{ccccccc}
\hline Oxides & $\mathrm{SiO}_{2}$ & $\mathrm{CaO}$ & $\mathrm{Fe}_{2} \mathrm{O}_{3}$ & $\mathrm{Al}_{2} \mathrm{O}_{3}$ & $\mathrm{SO}_{3}$ & $\mathrm{~K}_{2} \mathrm{O}$ \\
\hline wt\% & 53.8 & 4.39 & 8.87 & 25.35 & 1.15 & 2.23 \\
\hline
\end{tabular}

Table 2. Particulate loading comparison [6].

\begin{tabular}{ccc}
\hline & Engine & Laboratory \\
\hline Particulate Concentration (ppmw) & 0.02 & 33.3 \\
Operation Duration (hr) & 10000 & 6 \\
Particulate Loading (ppmw-hr) & $\mathbf{2 0 0}$ & $\mathbf{2 0 0}$ \\
\hline
\end{tabular}


The study by Murphy, Nix, Lawson, Straub, and Beer [6] found that deposition formed on only one side of the test articles. The one sided deposit formation was due to a large deposit structure forming on the transition piece of the test section. Figure 2 shows the transition piece with a deposit structure on the left side of the piece [14] [15]. The structure on the test section transition piece created a swirl effect leading to an uneven distribution of fly ash into the test section. This limited the areas of heavy deposition and created a "stratified" amount of deposition on the test articles. The swirl effect would be unrealistic in an actual gas turbine first stage vane flow.

The test articles used in this study are labeled and shown in Figure 3. Heavy deposition can be observed on the left side of the face on test article 1 (see Figure 3(a)). The roughness results were computed for the deposition on test article 1 using an Olympus LEXT OLS 3100 laser confocal microscope [14]. A detailed view of the roughness characteristics is shown in Figure 4(a) [14]. The blue line represents the mean average roughness of the article when unexposed to testing. The measurements to the peaks and valleys are represented by $\mathrm{y}_{\mathrm{i}}$, which is used to calculate the centerline averaged roughness $\left(\mathrm{SR}_{\mathrm{a}}\right)$ and the root-mean-square (RMS) roughness $\left(\mathrm{SR}_{\mathrm{q}}\right)$. $\mathrm{SR}_{\mathrm{p}}$ and $\mathrm{SR}_{\mathrm{v}}$ are defined as highest peak and lowest valley measure by $\mathrm{y}_{\mathrm{i}}$ respectively. Adding $\mathrm{SR}_{\mathrm{p}}$ and $\mathrm{SR}_{\mathrm{v}}$ gives the maximum peak-to-valley distance value, $\mathrm{SR}_{\mathrm{z}}$. Figure $4(\mathrm{~b})$ contains the image of where the surface roughness scan of the deposition was taken on test article 1 . The roughness values for test article 1 prior to sectioning are given in Table 3 [14].

In order to perform micro-indentation and SEM analysis, the test articles required prepping which included sectioning and trimming of the angle. The location of angle trimming can be seen in Figure 3(a). Flat samples were required to produce accurate results from the micro-indentation procedure. The samples have a substrate thickness of $1 / 4$ inches after the angle cut. Once the angle was removed, a grid for further sectioning was created to produce the test samples from flat test articles. Figure 5 details the sample labels for each test sample. The

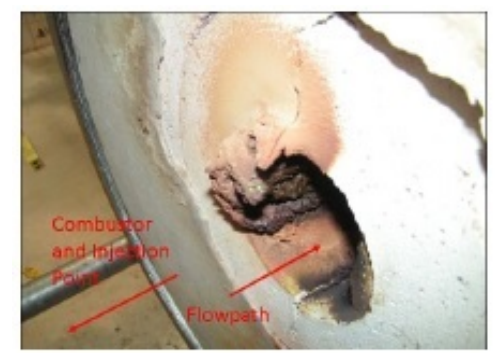

Figure 2. Image of large deposit formation on the left size of the transition piece [12].

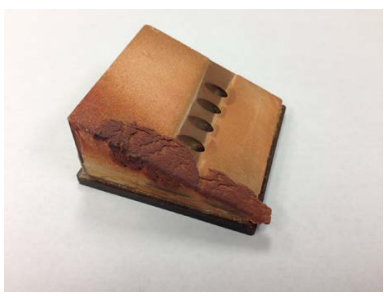

(a)

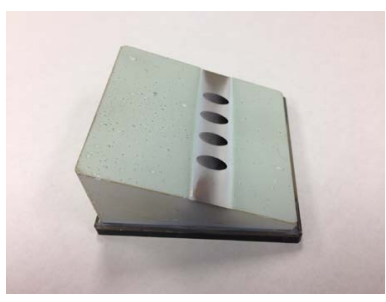

(b)

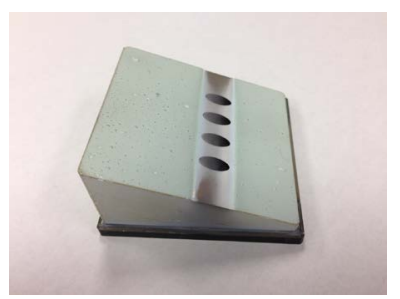

(c)

Figure 3. Labels of (a) Test Article $1^{\circ}-20^{\circ}$ with deposition; (b) unexposed Test Article $2^{\circ}-20^{\circ}$; and (c) Test Article $3^{\circ}$ $10^{\circ}$ with deposition. (a) Test Article 1; (b) Test Article 2; (c) Test Article 3.

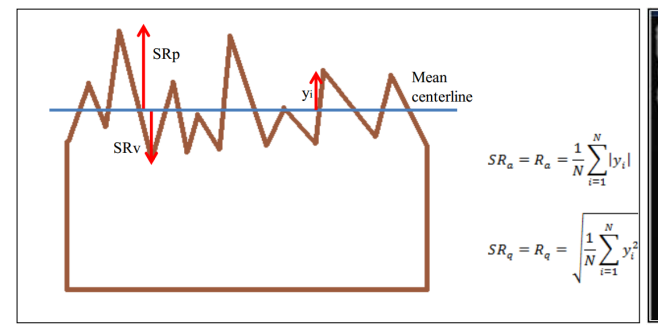

(a)

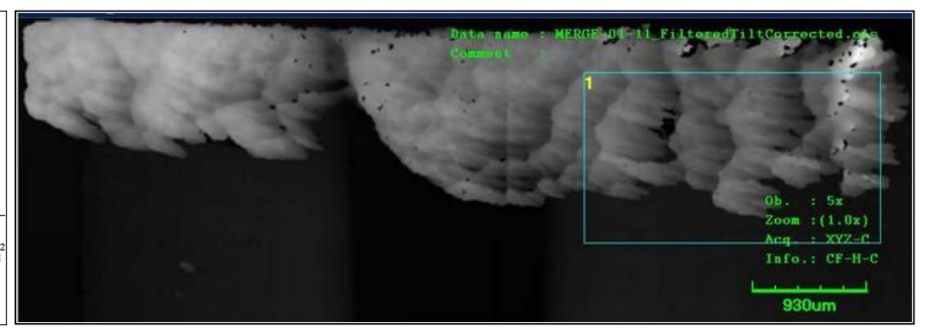

(b)

Figure 4. (a) Schematic of roughness values and (b) selected area for the roughness scan [12]. 
Table 3. Roughness characteristics for test article 1 [12].

\begin{tabular}{ccc}
\hline Parameter & Description of Roughness Parameters & Height $(\boldsymbol{\mu m})$ \\
\hline $\mathrm{SR}_{\mathrm{p}}$ & Maximum Peak Height & 399 \\
$\mathrm{SR}_{\mathrm{v}}$ & Maximum Valley Depth & 367 \\
$\mathrm{SR}_{\mathrm{z}}$ & Maximum Distance & 766 \\
$\mathrm{SR}_{\mathrm{a}}$ & Roughness Average & 79 \\
$\mathrm{SR}_{\mathrm{q}}$ & Root Mean Square Average & 100 \\
\hline
\end{tabular}

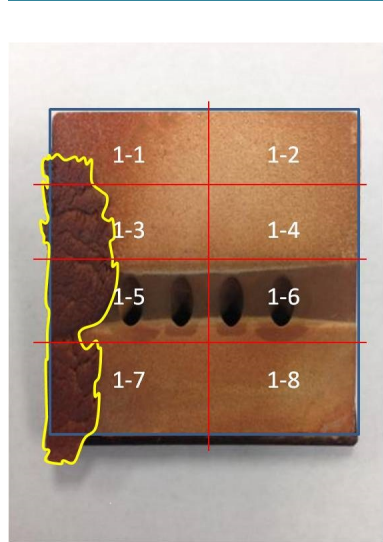

(a)

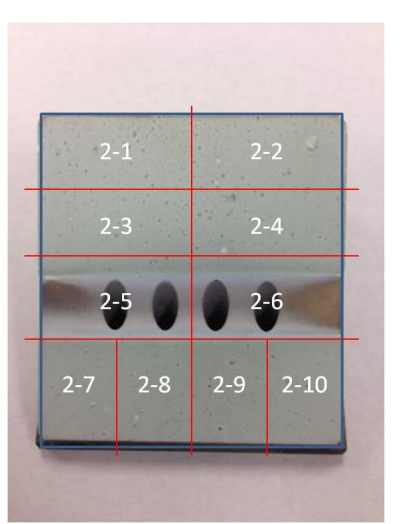

(b)

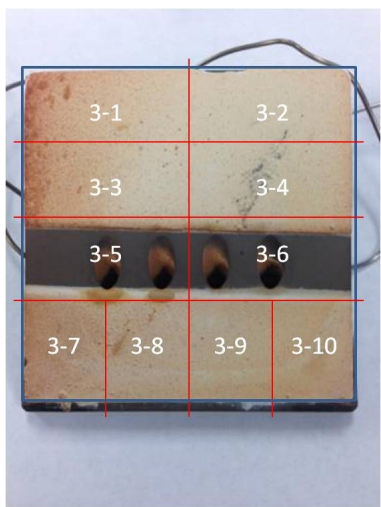

(c)

Figure 5. Cut list for (a) Test Article 1; (b) Test Article 2; and (c) Test Article 3.

heavy deposition on test article 1 in Figure 3(a) is outlined in Figure 5(a). Most of the deposition falls off during the sectioning, leaving only strongly adhered deposition that has reacted with the YSZ coating. After completion of the sectioning, samples devoid of defects (delamination, cracking, etc.) were used for micro-indentation tests on selected areas of varying deposition quantity.

For the micro-indentation test, a table top system was used for the multiple partial unloading procedure to determine the elastic modulus of the desired areas of the TBC samples at room temperature. The table top indentation system is comprised of a spherical tungsten carbide (WC) indenter having a radius of $793.5 \mu \mathrm{m}$, combined with a piezoelectric actuator (3.6 nm Resolution, Physik Instrumente, P-239.9S, $180 \mu \mathrm{m}$ ) and a high accuracy ( $\pm 0.15 \%$ Accuracy, Honeywell, Model 31, 100 lb.) load cell [9]. The shallow indentation depth $(50 \mu \mathrm{m}$ into the YSZ coating in the current study) allowed the test to be considered a non-destructive evaluation (NDE). The system is illustrated below in Figure 6 [9].

In order to perform a normalized elastic modulus analysis, the Young's modulus was determined for the unexposed Test Article 2 ( $E_{\text {unexposed }}$ ) using sections of Samples 2-3 and 2-4. Neither sample had been subjected to deposition testing. The samples were secured in a holder and underwent the multiple partial loading and unloading procedure. Indenter loading and unloading was performed throughout each of the top surfaces of the samples' top coat. An uncertainty analysis was performed on the strain tolerance results in order to show the effect of measurement uncertainties on the accuracy of the elastic moduli results. A root-sum-square (RSS) combination was used to incorporate the uncertainties from the multiple-sample data and pertubated measurement/ system errors associated with the table top system [16].

Scanning electron microscopy (SEM) was used to provide high resolution images of cross sections of the samples and the top surface of the YSZ coating, and energy dispersive X-ray spectroscopy (EDS) was completed to determine of the elemental composition of regions of interest (Hitachi S-4700 or JEOL JSM-7600F).

\section{Results and Discussion}

Prior to any micro-indentation, confirmation that the molten deposit on top of the TBC ceramic top coat agreed with the elemental composition of fly ash injected into the combustion facility (Table 2) was examined. Figure 7 shows a SEM micrograph of a cross-section of Sample 3-1 near the columnar tips of the YSZ coating. An $\mathrm{X}$-ray spectrum was acquired at a single point within the deposition layer (circled in Figure 7). 


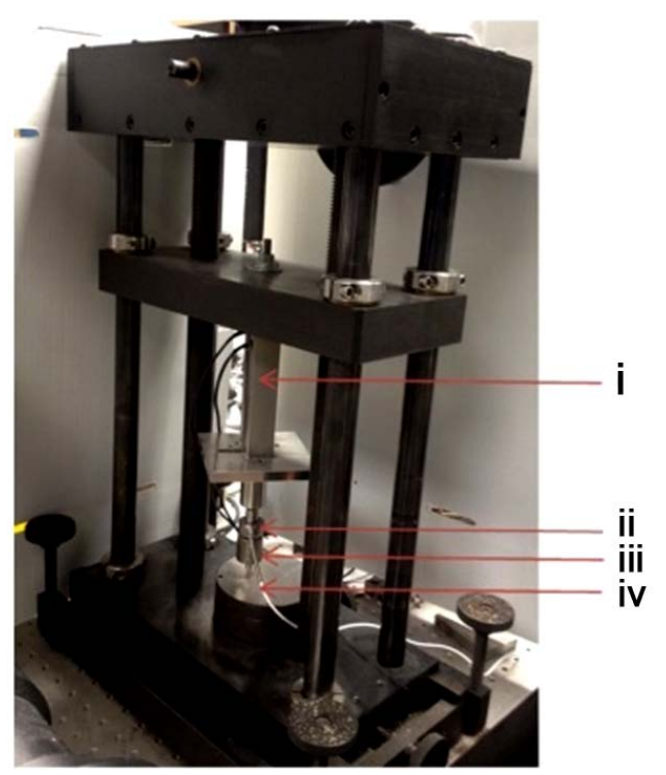

Figure 6. Table top micro-indentation setup: (i) $3.6 \mathrm{~nm}$ Resolution, Physik Instrumente, P-239.9S, $180 \mu \mathrm{m}$ piezoelectric actuator; (ii) $\pm 0.15 \%$ Accuracy, Honeywell, Model 31, $100 \mathrm{lb}$. load cell; (iii) spherical tungsten carbide (WC) $793.5 \mu \mathrm{m}$ radius indenter; and (iv) sample stage [8].

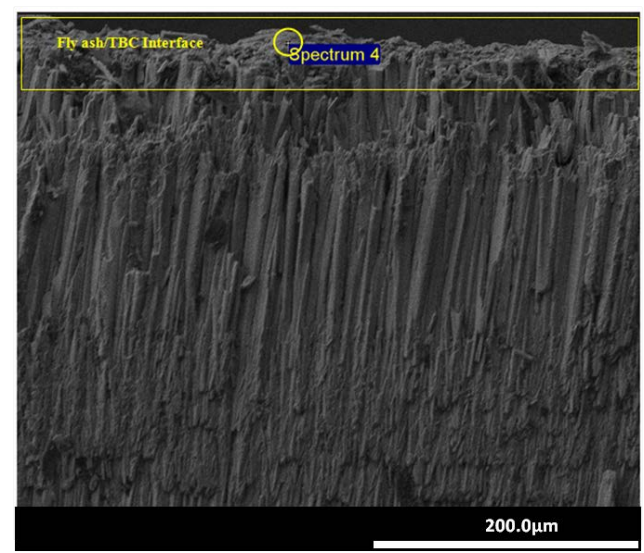

Figure 7. Point \& ID location on Sample 3-1 for acquisition of spectrum results in Table 4.

Table 4 has the comparison between original processed fly ash and the results obtained from the spectrum analysis by weight percentage. Silicon, aluminum, and oxygen were chosen as elements of interest since they have the highest weight percentage in Table 1 . Based on the elemental distribution content, Table 4 confirmed that the adhering deposits were molten and cooled processed fly ash.

Figure 8(a) shows the top view of as-deposited YSZ coating that has been unexposed to any combustion facility testing. The columnar structure with inter-columnar gaps improved the lateral strain compliance of the coatings. The top view of the YSZ top coat with molten fly ash are shown in Figure 8(b). Once molten and cooled, the deposits formed a thin, hardened, and almost glass-like ash layer on top of the columns of the YSZ coating. This subsequently reduced to the stain tolerance of the YSZ coating.

As the molten deposits infiltrated top coat, the YSZ coating became more susceptible to delamination. Upon sectioning, a portion of Sample 1-7 developed a diagonal crack along the top surface of top coat which later led to delamination (see Figure 9(a)). Figures 9(b)-(c) show that Sample 1-3 lost roughly $100 \mu \mathrm{m}$ of YSZ coating near the edge where deposition was abundant. Spallation of the TBC layers is considered the final failure of the insulating system. 
Table 4. Comparison between processed fly ash and molten deposits by weight percentage.

\begin{tabular}{cccc}
\hline Constituent/wt\% & Si & Al & O \\
\hline Original Fly Ash & 28.09 & 14.98 & 51.74 \\
Molten Deposit & 19.51 & 13.61 & 53.40 \\
\hline
\end{tabular}

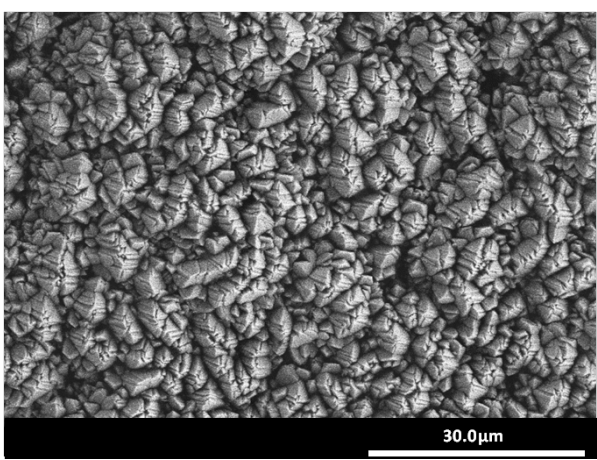

(a)

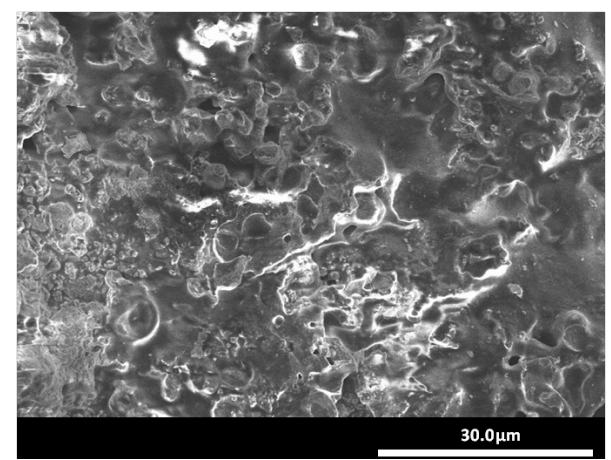

(b)

Figure 8. Top view of (a) unexposed Samples 2-1 and (b) molten deposition on Sample 1-5.

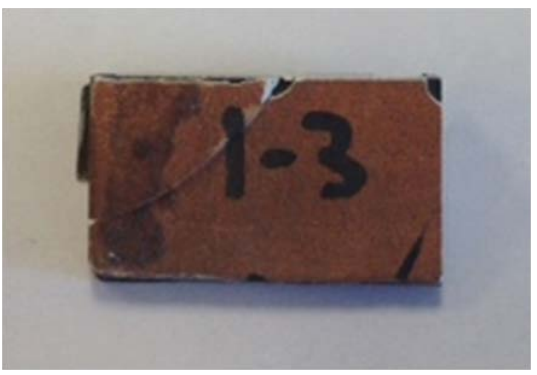

(a)

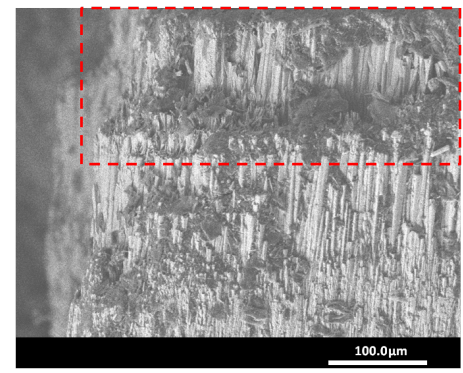

(b)

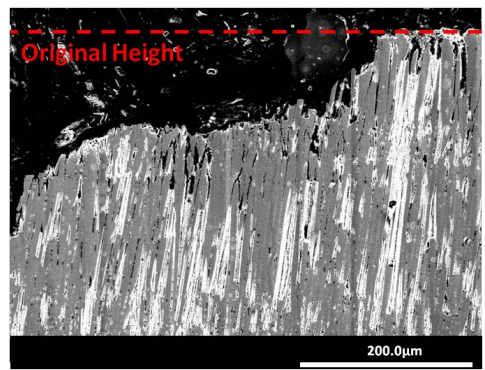

(c)

Figure 9. (a) Top view of Sample 1-7 and cross-section micrographs of delamination in Sample 1-3 top coating (b) after sectioning and (c) after mounting and polishing. (a) Sample 1-7: Top coat cracking; (b) Post-sectioning/Pre-polishing; (c) Mounted in a conductive mounting media.

Figure 10 below contains an image of the two unexposed samples, 2-3 and 2-4, and their averaged elastic modulus are recorded below in test sample images. The error bars in on the results denoted the uncertainty for each sample. An average of all the individual tests on both samples was used to obtain a value for the baseline elastic modulus $\left(\mathrm{E}_{\text {unexposed }}\right)$ of $20.93 \mathrm{GPa}$. The uncertainty was measured as a combination of the number of indentations on each sample and the tolerance of the table top system.

Once the value of $E_{\text {unexposed }}$ was obtained, multiple partial unloading was performed on Samples 1-1, 1-2, 1-3, 1-4, 3-1, and 3-2. Figure 11(a) contains the images and results for Samples 1-1 and 1-2. The colored dashed boxes in the images of the samples correspond with the averaged elastic modulus value in the lower chart of Figure 11(a). The portion of Sample 1-1 bordered with the blue dashed box contained an area where molten deposits had adhered onto the TBC prior to the sectioning. The infiltrated area exhibited a higher modulus of elasticity than those of the unexposed articles or areas along the same sample or same plane without any significant deposition adherence. The same increase in Young's modulus can be observed for Samples 1-3 and 1-4 (Figure 11(b)) and Samples 3-1 and 3-2 (Figure 11(c)). The elastic modulus for Sample 3-1 was recorded for the area with deposition only due to sample compliance issues.

In order to develop a trend for the molten deposits effects on the TBC, the modulus of elasticity with respect to the length across the TBC top face was plotted. The width of the top face, which is used for a length scale, of all the TBC coated articles is roughly 2 inches (see Figure 12).

Individual indenter results for all samples were plotted in Figure 13. The graph contains the normalized distance $(\mathrm{x} / \mathrm{W})$ versus normalized Young's modulus values $\left(\mathrm{E}_{\mathrm{i}} / \mathrm{E}_{\text {unexposed }}\right)$. A power series trendline was included for 


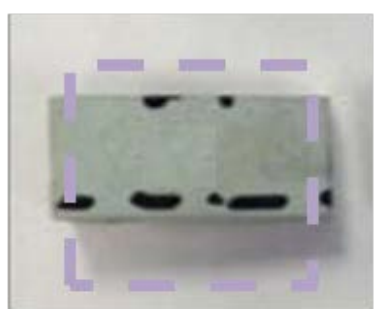

Samples 2-3

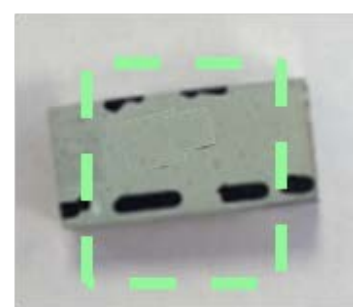

Sample 2-4

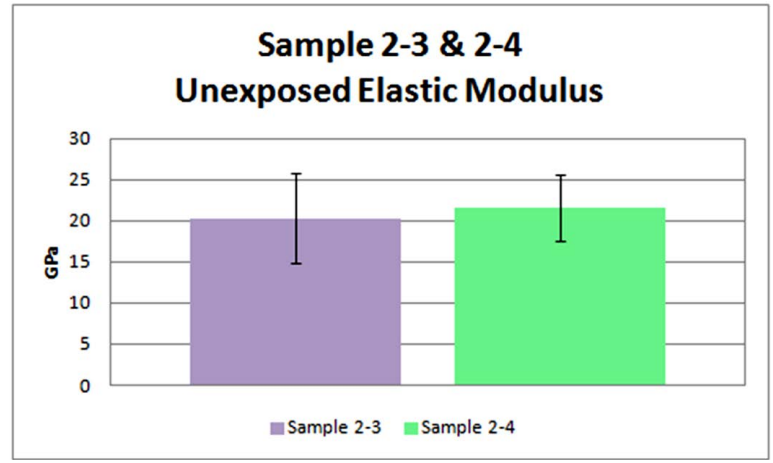

Figure 10. Images of unexposed Samples 2-3 and 2-4 and their average values for TBC modulus of elasticity.

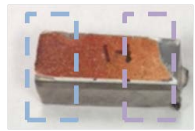

Sample 1-1

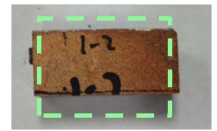

Sample 1-2

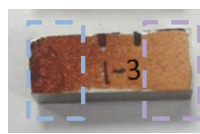

Sample 1-3

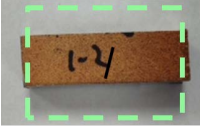

Sample 1-4

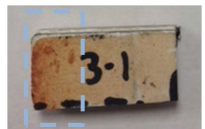

Sample 3-1

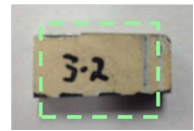

Sample 3-2

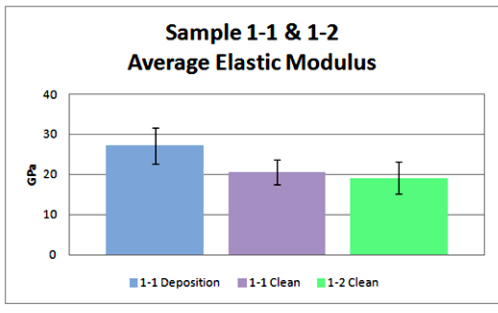

(a)

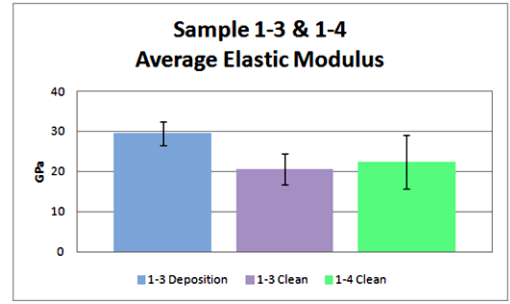

(b)

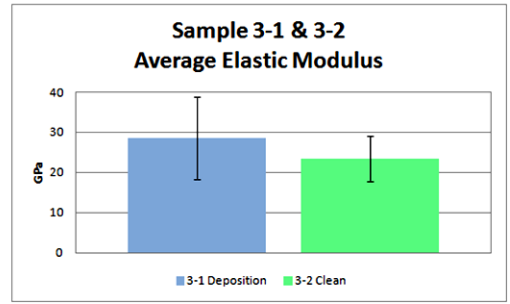

(c)

Figure 11. Image of samples and their values for averaged TBC modulus of elasticity for (a) Samples 1-1 and 1-2; (b) Samples 1-3 and 1-4; and (c) Samples 3-1 and 3-2.

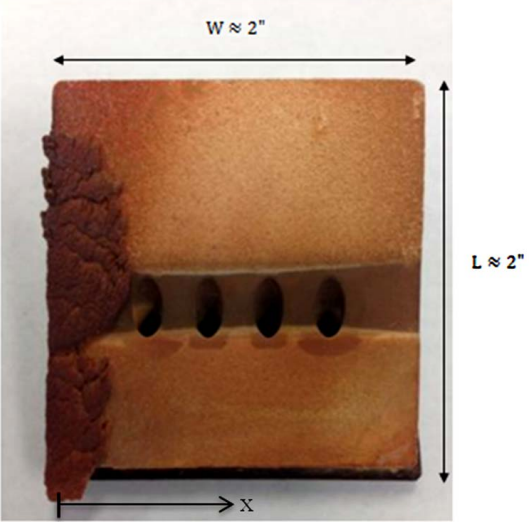

Figure 12. Dimensions of the test article faces. 


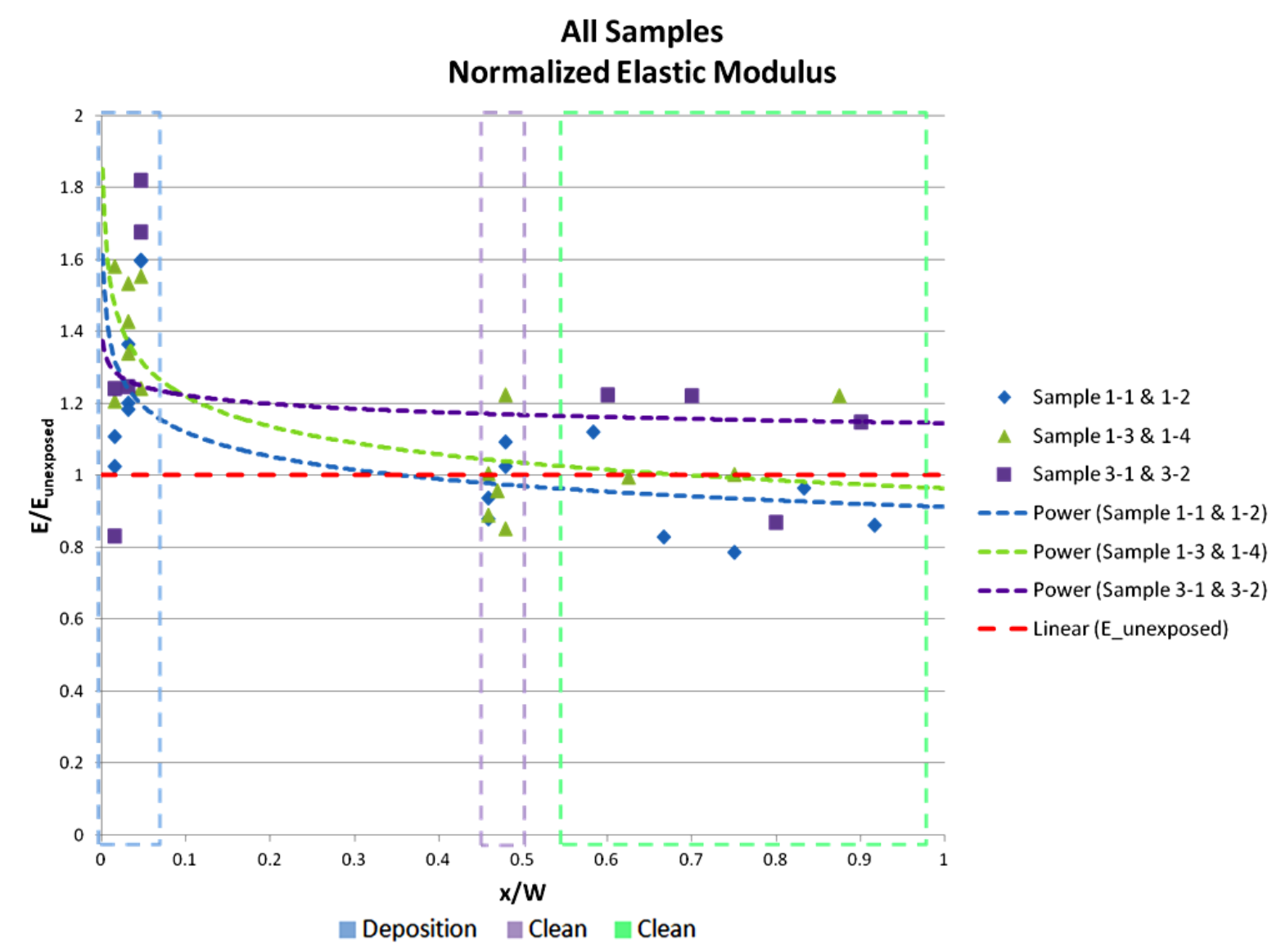

Figure 13. Normalized elastic modulus trends for all samples.

each sample set to show the relationship between the surface stiffness from near the $\mathrm{x} / \mathrm{W} \approx 0$ edge to the right side of the test article face. The error was not plotted in Figure 13 in an attempt to not clutter the plot and was already shown in Figure 11. The trend for Samples 1-1 \& 1-2 and Samples 1-3 \& 1-4 show that there was a reduction in the strain tolerance of the YSZ coating in an area of depositi on infiltration, and that the modulus of elasticity approaches the baseline Young's modulus of the unexposed test articles as $\mathrm{x}$ approaches 2 inches where there was significantly less deposition. The two aforementioned power series lines share a similar trend since the samples were from the same test articles. The difference in modulus of elasticity was less between for Samples 3-1 and 3-2, which was most likely due to less molten fly ash contaminants.

\section{Conclusions}

This purpose of the current study was to analyze the effects on the mechanical properties of TBC coating systems from syngas particulate molten deposits after Murphy, Nix, Lawson, Straub, and Beer completed work on the effects of the particulate deposition on gas turbine vane film cooling [6]. The molten deposits from the fly ash were found to adhere onto the YSZ top coatings and penetrate the YSZ coating to a maximum distance of 20 $\mu \mathrm{m}$. With the use of a micro-indentation technique, the modulus of elasticity was recorded for unexposed TBC, lightly exposed TBC, and deposition-infiltrated TBC.

The molten deposits lead to an increase in the Young's modulus and thus, degradation of the strain tolerance of the DVD YSZ coating. Once the deposits were cooled on the top coat, the YSZ layer had a higher tendency to delaminate. A micro-indentation method was used to quantify the elastic modulus of the layer, and it was found that areas with molten deposit infiltration experienced an increase in the surface stiffness. This increase corresponds with a reduction in the strain tolerance of the top coat. The stress mismatch between exposed and unexposed TBC from the interaction between the fly ash deposition and YSZ coating will result in spallation of the ceramic top coat. 


\section{Acknowledgements}

The authors would like to acknowledge the support of the Department of Energy, Office of Science, Experimental Program to Stimulate Competitive Research (EPSCoR) under grant/contract number DE-FG02-09ER46615, monitored by Dr. Tim Fitzsimmons. In addition, the project was partially funded by the US Department of Energy, National Energy Technology Laboratory through a cooperative agreement with EPSCoR. There are several people that deserve acknowledgments for their contributions to this project. The authors would like to thank Dr. Keith Kruger of Haynes, International for donating the Haynes 230 test article material. Dr. Derek Hass and Balvinder Gogia of Directed Vapor Technologies International, Inc. (DVTI) cost shared the thermal barrier coatings and bond coat applied to the test articles. Westmoreland Mechanical Testing \& Research, Inc. sectioned the angled test articles into the test samples. Mounting and polishing of the samples were completed by Metallurgical Technologies, Inc. Gratitude also goes out to the Shared Research Facilities and the Chemical Engineering Department at West Virginia University for the cleanroom access and training for the use of the SEM and other microscopy preparation techniques.

\section{References}

[1] Padture, N.P., Gell, M. and Jordan, E.H. (2002) Thermal Barrier Coatings for Gas-Turbine Engine Applications. Science AAAS, 296, 280-284. http://dx.doi.org/10.1126/science.1068609

[2] Schulz, U., Leyans, C., Fritscher, K., Peters, M., Saruhan-Brings, M., Lavigne, O., Dorvaux, J.-M., Poulain, M., Mévrel, R. and Caliez, M. (2003) Some Recent Trends in Research and Technology of Advanced Thermal Barrier Coatings. Aerospace Science and Technology, 7, 73-80. http://dx.doi.org/10.1016/S1270-9638(02)00003-2

[3] Wellman, R.G. and Nicholls, J.R. (2000) Some Observation on Erosion Mechanisms of EB PVD TBCs. Wear, 242, 89-96. http://dx.doi.org/10.1016/S0043-1648(00)00391-4

[4] Levi, C.G., Hutchinson, J.W., Vidal-Sétif, M.-H. and Johnson, C.A. (2012) Environmental Degradation of ThermalBarrier Coatings by Molten Deposits. MRS Bulletin, 37, 932-941. http://dx.doi.org/10.1557/mrs.2012.230

[5] Drexler, J.M., Gledhill, A.D., Shinoda, K., Vasiliev, A.L., Reddy, K.M., Sampath, S. and Padture, N.P. (2011) Jet Engine Coatings for Resisting Volcanic Ash. Advanced Materials, 23, 2419-2424.

http://dx.doi.org/10.1002/adma.201004783

[6] Murphy, R.G., Nix, A.C., Lawson, S.A., Straub, D. and Beer, S.K. (2012) Preliminary Experimental Investigation of the Effects of Particulate Deposition on IGCC Turbine Film-Cooling in a High-Pressure Combustion Facility. ASME Turbo Expo 2012: Turbine Technical Conference and Exposition, 4, 979-986. http://dx.doi.org/10.1115/GT2012-68806

[7] Eberl, C., Gianola, D.S., Wang, X., He, M.Y., Evans, A.G. and Hemker, K.J. (2011) A Method for in Situ Measurement of the Elastic Behavior of a Columnar Thermal Barrier Coating. Acta Materialia, 59, 3612-3620. http://dx.doi.org/10.1016/j.actamat.2011.02.034

[8] Tannenbaum, J.M. (2011) Progression in Non-Destructive Spallation Prediction and Elevated Temperature Mechanical Property Evaluation of Thermal Barrier Coating Systems by Use of a Spherical Micro-Indentation Method. Ph.D. Dissertation, West Virginia University, Morgantown.

[9] Otunyo, D.A. (2012) Mechanical Property Evaluation of Thermal Barrier Coating Systems at Elevated Temperatures by Use of Spherical Micro-Indentation Method. M.S. Thesis, West Virginia University, Morgantown.

[10] Hass, D. (2012) Thermal Barrier Coating Environmental Durability Enhancement (CMAS). NAVAIR, N06-032.

[11] Gleeson, B., Wang, W., Hayashi, S. and Sordelet, D.J. (2004) Effects of Platinum on the Interdiffusion and Oxidation Behavior of Ni-Al-Based Alloys. Material Science Forum, 461, 213-222. http://dx.doi.org/10.4028/www.scientific.net/MSF.461-464.213

[12] Dorrington, J.R., Bogard, D.G. and Bunker, R.S. (2007) Film Effectiveness Performance for Coolant Holes Imbedded in Various Shallow Trench and Crater Depressions. ASME Turbo Expo 2007: Power for Land, Sea, and Air, 4, 749-758. http://dx.doi.org/10.1115/GT2007-27992

[13] Lawson, S.A. and Thole, K.A. (2011) Effects of Simulated Particle Deposition on Film Cooling. Journal of Turbomachinery, 133, 021009-1-021009-10. http://dx.doi.org/10.1115/1.4000571

[14] Murphy, R.G. (2012) Experimental Investigation of Particulate Deposition on a Simulated Film-Cooled Turbine Vane Pressure Surface in a High Pressure Combustion Facility. M.S. Thesis, West Virginia University, Morgantown.

[15] Murphy, R.G., Nix, A.C., Lawson, S.A., Straub, D. and Beer, S.K. (2013) Investigation of Factors that Contribute to Deposition Formation on Turbine Components in a High-Pressure Combustion Facility. ASME Turbo Expo 2013: Tur- 
bine Technical Conference and Exposition, 3B, V03BT13A027-V03BT13A027.

[16] Moffat, R.J. (1998) Describing the Uncertainties in Experimental Results. Experimental Thermal and Fluid Science, 1, 3-17. http://dx.doi.org/10.1016/0894-1777(88)90043-X

\section{Nomenclature}

E: Young's modulus

k: Thermal conductivity

SR: Surface roughness

$\mathrm{W}$ : Width of the test article face

$\mathrm{x}$ : Distance along the test article face

$\mathrm{y}$ : Distance from the mean centerline for surface roughness measurement

\section{Subscripts}

a: Averaged surface roughness

p: Peak of surface roughness

q: Root-mean-square surface roughness

unexposed: Unexposed test article index

$\mathrm{v}$ : Valley of surface roughness

z: Distance from peak to valley 
Scientific Research Publishing (SCIRP) is one of the largest Open Access journal publishers. It is currently publishing more than 200 open access, online, peer-reviewed journals covering a wide range of academic disciplines. SCIRP serves the worldwide academic communities and contributes to the progress and application of science with its publication.

Other selected journals from SCIRP are listed as below. Submit your manuscript to us via either submit@scirp.org or Online Submission Portal.
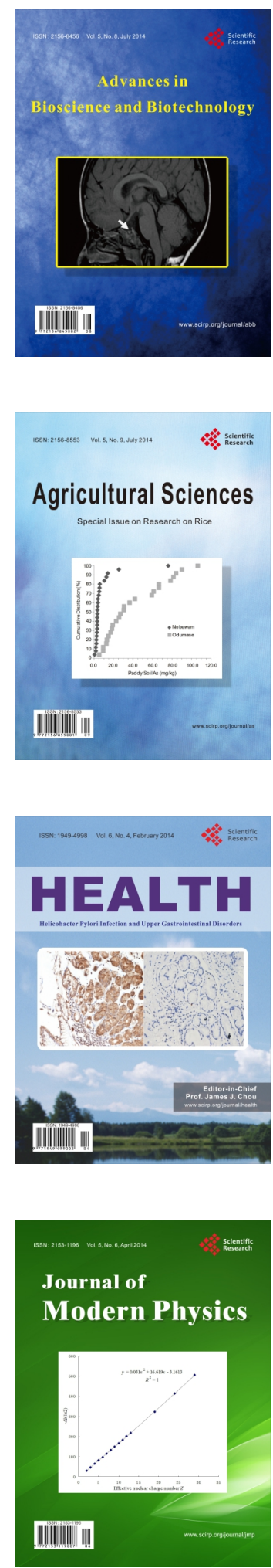
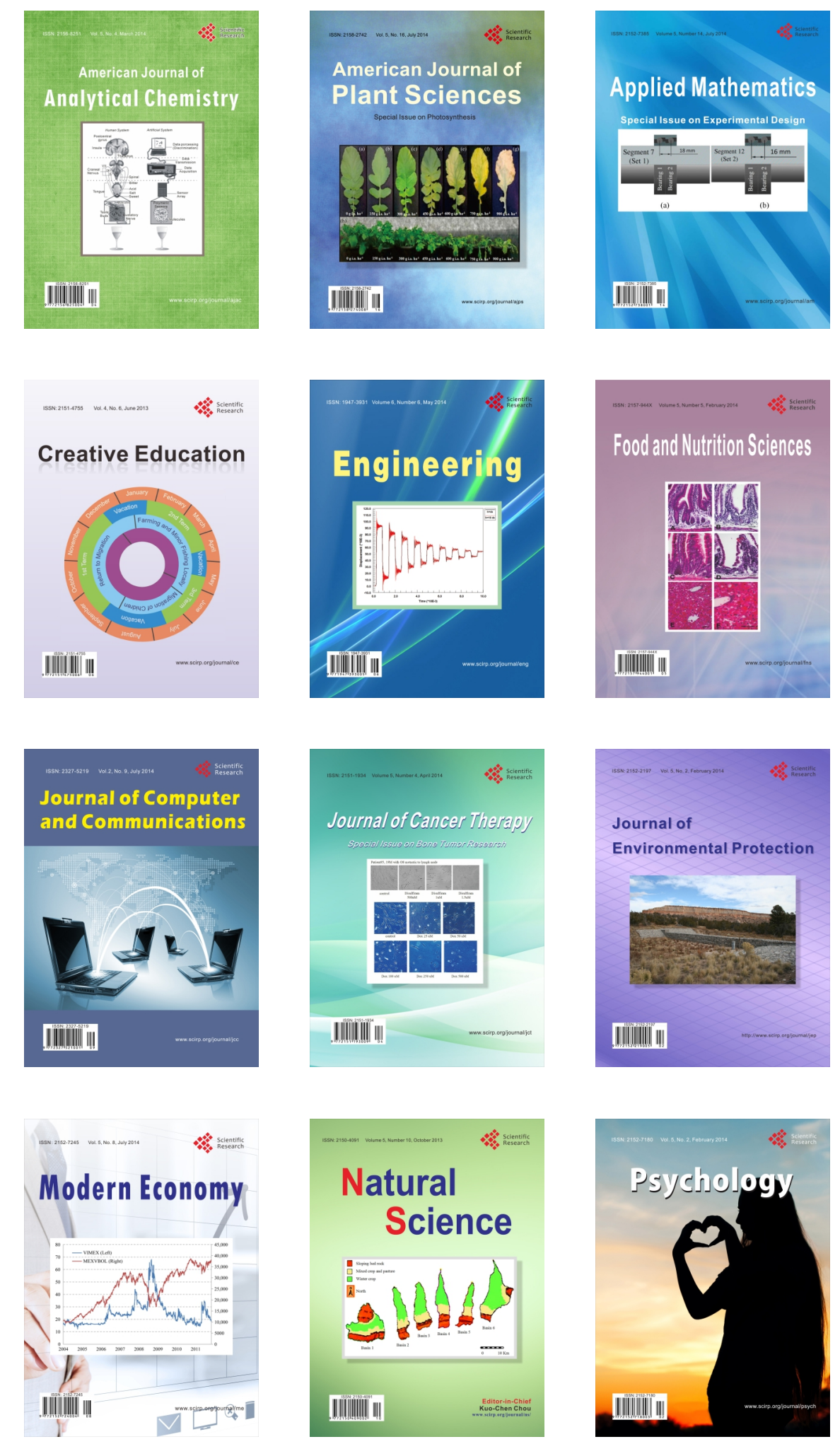